IJ§ER

ISSN: 2149-5939
International Journal of Social Sciences and Education Research

Online, http://dergipark.gov.tr/ijsser

Volume: 3(3), 2017

\title{
Bir hayali cemaat olarak futbol taraftarının geleneksel ve yeni medya kullanımının karşılaştııılmas ${ }^{1}$
}

\section{Comparing traditional media and new media use of football supporters as an imagined community}

Aysel $\mathrm{Ay}^{2}$

Received Date: 02 / 02 / 2017

Accepted Date: 03 / $06 / 2017$

$\ddot{O} z$

Benedict Anderson'a ait olan "hayali cemaat" kavramı, aynı aidiyet dinamiklerine sahip tüm gruplar için kullanılabilmektedir. Futbol taraftarlı̆̆ da tıpkı Anderson'ın ulus için kullandı̆̆ hayali cemaat kavramı gibi bir futbol takımı etrafinda oluşan hayali cemaati yansıtmaktadır. Hayali cemaatin olușumunu sağlamada ve varlığın pekiştirmede medya ise önemli bir yere sahiptir. Ancak geleneksel ve yeni medya araçlarından hangisinin daha etkili olduğu tartışılmaktadır. Bu bağlamda çalıșmada, geleneksel ve yeni medya kullanımının futbol taraftarlarının grup aitliğini pekiştirmesindeki rolü odak grup çalışması ile değerlendirilecektir.

Anahtar sözcükler: Hayali cemaatler, futbol, taraftar, geleneksel medya, yeni medya.

\begin{abstract}
Coined by Benedict Anderson, the term "imagined community" is also used for all the groups with common sense of belonging dynamics. Football supporting echoes an imagined community notion around a football team, as Anderson's term used for a nation. Media is in an important position enabling the constitution and reinforcement of imagined community. It has been debated, however, if traditional or new media tools are more effective in this constitution and reinforcement. This study, in this context, aims to shed light on the role of traditional and new media use in strengthening sense of group belonging of football supporters through focus group method.
\end{abstract}

Keywords: Imagined communities, football, supporter, traditional media, new media.

\section{Giriş}

Kitle iletişim araçlarının toplumsallaşmayı sağlamadaki rolünün yanında hayali cemaat oluşturmada önemli bir yere sahip olduğu bilinmektedir. Benedict Anderson'ın kapitalist yayıncılık ile açıkladığı hayali cemaat oluşumu, günümüzde geleneksel medyanın yanı sıra yeni medya önemli etkisi ile farklı bir boyuta taşınmıştır. Ancak, hangi medya biçiminin hayali cemaatler oluşturmada veya mevcut hayali cemaatlerin varlığını pekiştirmede daha etkili olduğu diğer bir tartışma konusudur.

Spor faaliyetleri içinde oldukça geniş bir kitleye hitap eden futbol ise, başlı başına bir hayali cemaati var etmektedir. Futbol taraftarlarından oluşan bu hayali cemaate aidiyeti pekiştiren medyanın, geleneksel ve yeni araçlarından hangisinin taraftarlarca tercih edildiği bu çalışmanın sorunsalını oluşturmaktadır. Bu bağlamda çalışmanın amacı; bir nitel araştırma yöntemi olan

\footnotetext{
${ }^{1}$ ICSSER (2017-Roma) 3. Uluslararası Sosyal Bilimler \& Eğitim Araştırmaları Konferansında sözlü bildiri olarak sunulmuştur.

${ }^{2}$ Arş.Gör.Dr.,Marmara Üniversitesi İletişim $\quad$ Fakültesi $\quad$ Gazetecilik Bölümü, İstanbul/Türkiye,aysel.ay@marmara.edu.tr
} 
Ay, A. (2017). Comparing traditional media and new media use of football supporters as an imagined community. International Journal of Social Sciences and Education Research, 933-944.

odak grup aracılığıyla, futbol taraftarlarının hayali cemaat aidiyetlerini pekiştirirken ve sosyalleşirken hangi kitle iletişim araçlarını tercih ettiklerini tespit etmektedir.

\section{Hayali cemaat}

Benedict Anderson tarafindan ortaya atılan "hayali cemaat" kavramı temel olarak, ulusun ve ulusal bilincin oluşumunu açıklamaktadır. Anderson ulus ve hayali cemaat ilişkisini şöyle anlatmaktadır (Anderson, 2013, s. 20-21);

"Ulus hayal edilmiş bir siyasal topluluktur-kendisine aynı zamanda hem egemenlik hem de sinırlılık içkin olacak şekilde hayal edilmiş bir cemaattir. Hayal edilmiştir, çünkü en küçük ulusun üyeleri bile diğer üyeleri tanımayacak, onlarla tanışmayacak, çoğu hakkında hiçbir şey işitmeyecektir ama yine de her birinin zihninde toplamlarının hayali yaşamaya devam eder... Ulus sinırlı olarak hayal edilir, çünkü belki de bir milyar insanı kapsayan en büyüğ̈̈nün bile, ötesinde başka uluslara mensup insanların yaşadiğl, esnek de olsa sonlu sinırlarl vardır. Hiçbir ulus kendisini insanliğın tümü ile örtüşüyor olarak hayal etmez... Ulus egemen olarak hayal edilir, çünkü kavram, Aydınlanma ve Devrim'in, ilahi olarak buyrulmuş, hiyerarşik hanedanlık mülklerinin meşruiyetini aşındırmakta olduğu bir çağda doğmuştu."

Anderson, ulus anlayışını dolayısıyla hayali bir cemaat oluşumunu anlatırken "kapitalist yayıncılık'a dikkat çekmektedir. Anderson, bu kavramla kitap yayıncılığın dünyanın birçok yerine yayılması ile eşzamanlı olarak birbirine bağlanan ancak birbirini tanımayan toplumları ifade etmektedir. Daha sonraları gazetenin ortaya çıkması ile hayali cemaatlerin varlığı güçlenmiştir. Gazeteler aracılığıyla bireyler her sabah aynı ayini yapmakta, dünyevi olan bir uğraşla aynı zamanda meşgul olmaktadırlar. Bireyler, hayali bir dünyanın etrafında aynı şeyleri düşünmekte, aynı düşünce etrafinda birbirlerinden habersiz toplanmaktadırlar. Eskiden kutsal yazı dillerine sahip olan büyük dinlerin (Hristiyanlık ve İslam gibi) metinleri üzerinden kendilerini ifade eden ve bu sayede kıtalar ötesi bir dayanışma sağlayan bireyler için artık bunu kitle iletişim araçları gerçekleştirmektedir (Anderson, 2013, s. 44-55).

\section{Futbol ve futbol taraftarlığı}

İnsanoğlu var olduğundan bu yana farklı oyun biçimleri ile de olsa topu kullandığı bilinmektedir. Ancak futbolun başlangıcı için kesin bir tarih vermek güçtür. Ortaçağ'da Romalı askerler ve Fransızlar tarafından oyanan "Le Soule" adlı oyun futbol ile benzer özellikler taşımaktadır. Ancak bugünkü anlamda futbolun ilk kez ortaya çıtı̆ğ yer İngiltere'dir (Türkiye Futbol Federasyonu Yayınları, 1992, s. 8-9).

Futbolun Türkiye topraklarına gelişi ise, ticari yönden küreselleşmenin hissedildiği ve Osmanlı İmparatorluğu'nun halen hüküm sürdüğü 19. yüzyıl sonlarında rastlamaktadır. İlk olarak Osmanlı topraklarında yaşayan Rumlar ve İngilizler arasında başlayan futbol, Selanik ve Bornova'da başlamış Kadıköy'e kadar yayılmış, daha sonraları müsabakaya dönmüştür. Bir Türk futbol takımın kurulması ise Mekteb-i Sultani (Galatasaray Lisesi) öğrencileri ve onlara önayak olan Ali Sami Yen'in girişimiyle gerçekleşmiştir. Daha sonra "Galatasaray" olarak anılan bu futbol takımı 1905-1906 sezonunda "İstanbul Futbol Ligi”ne katılan ilk Türk takımı olmuştur. Sonraki yıllarda yeni takımlar kurulmuştur. Türkiye Cumhuriyet'inin kurulmasının ardından Ankara Futbol Ligi de kurulmuş, Türkiye'nin farklı yerlerinde takımlar kurulması ile birlikte, başta İstanbul, Ankara ve İzmir takımları olmak üzere Türkiye ligi 1936 yılında "Milli Küme" etrafinda bir araya gelmiştir. Türk futbolunda ilk Profesyonel Futbol Ligi 1951-1952 sezonunda 
Ay, A. (2017). Bir hayali cemaat olarak futbol taraftarının geleneksel ve yeni medya kullanımının karş1aștırılması. International Journal of Social Sciences and Education Research, 933-944.

İstanbul'da kurulmuş, günümüze kadar farklı isimler alarak gelişmiştir (Türkiye Futbol Federasyonu Yayınları, 1992, s. 9-79).

Her oyunda olduğu gibi futbolda da iki farklı takım ya da grubun karşı karşıya gelmesi, oyun dışında kalanların tarafını seçmesine neden olmuştur. Bu nedenle, bir oyun olarak ortaya çıkan futbol, seyirci karşısına çıktığı günden beri taraftarlığı da ortaya çıkarmıştır.

\section{Hayali cemaat ve futbol taraftarlı̆g}

Anderson'ın sözünü ettiği "hayali cemaat" kavramı her ne kadar bir ulusa ve bu ulusun kimlik inşasındaki rolüne atıfta bulunsa da aslında bu kavram birçok grup biçiminin oluşumunu da anlatmaktadır. Bir ulus içinde bireyler aynı duygular, aynı tarih ve aynı kültürel kodlar aracılığıyla bir araya geldiği gibi, farklı grup yapıları da benzer dinamiklerin etkisinde ortaya çıkmaktadır. Bu gruplar içinde futbol taraftarlığı da benzer aidiyet duyguları, kültürel kodlar ve takımın geçmişi, başarıları gibi etkenler etrafında bir araya gelmektedir. Bir ulusa aitliği simgeleyen bayrak, dil ve benzeri içerikler olduğu gibi bir futbol taraftarı için de kendi takım bayrağı, renkleri vardır. Ayrıca bir ulus için milliyetçilik kavramı ile şekillenen bu simgelerin birleştirici özelliği futbol taraftarlığı için de anılabilir.

Bunun yanında, Anderson, kapitalist yayıncılık söylemi ile toplumlardaki bireylerin 'okur' olarak hayali bir cemaatin üyesi haline geldiğinden söz etmektedir. Ayrıca Anderson, gazeteciliğin yayılması ile bu hayali cemaat aidiyetliği bir 'ulus'a ya da bir 'ırk'a bağlılığı daha da pekiştirdiğini dile getirmektedir (Anderson, 2013, s. 30-51). Benzer bir şekilde, bir futbol taraftarı tuttuğu takım aracılığıyla bir hayali cemaatin üyesi olurken, kendisinden başka aynı takım taraftarlarının olduğunu bilmekte ve tanımadığı bu kitleye ile ilk olarak geleneksel medya aracılığıyla bağlanmış olmaktadır. Yeni medya ile birlikte etkileşimin artması ve hız, ulus için gazeteciliğin yayılmasındaki etkileri hatırlatmaktadır.

\section{Geleneksel ve yeni medya}

Yazının icadından bugüne gerek kişiler arası gerekse kitlelere yönelik iletişim araçları tarihte yerini almıştır. Gazetenin on yedinci yüzyılda ortaya çıkışından 19. yüzyılın ikinci yarısına kadar sadece yazılı olan kitle iletişimi, radyonun icadı ile işitsel hale gelmiş, yirminci yüzyılın başlarında, özellikle de Birinci Dünya Savaşı'nda askeri bir propaganda aracı olarak önemli bir yere sahip olmuştur. 1930'lu yıllardan sonra görsel iletişimin en önemli araçlarından biri olan televizyonun yavaş yavaş kitlelere ulaşma yolunda ilerlemesi ve 1950'lili yıllarda daha geniş bir izleyici kitlesi ile buluşması, radyonun dinlenirliğini yok edeceğini düşündürse de günümüze kadar, hem radyo hem televizyon varlığını gelişerek sürdürmüştür.

Bunun yanında, 19. yüzyılın son çeyreğinde ortaya çıkan bilgisayar teknolojileri ve buna bağlı olarak ortaya çıkan internet, yukarıda anılan araçların "geleneksel" olarak adlandırılmasına neden olacak kadar büyük bir etki alanı oluşturmuş ve ortaya "yeni medya" kavramını çıkarmıştır. Bilgisayar teknolojilerinin ortaya çıktığı günden bu yana geçen süreç ise, kitle iletişim araçlarının kısa tarihinin en hızlı yazıldığı dönemi yansıtmaktadır. 
Ay, A. (2017). Comparing traditional media and new media use of football supporters as an imagined community. International Journal of Social Sciences and Education Research, 933-944.

\section{Medya ve futbol taraftarları}

Anderson'ın aşağıdaki ifadeleri medyanın futbol taraftarlığını pekiştirmedeki muhtemel etkisi hakkında önemli ipuçlarına sahiptir.

“...yeni ulusal toplulukların hayal edebilirliğine asll olumlu etkide bulunan, yeni bir üretim ve üretim ilişkileri sitemi (kapitalizm), bir iletişim teknolojisi (matbaa) ve insanlı̆̆ın mahkûm olduğu dilsel çeşittilik arasındaki, belki de rastlantısal ama altüst edici etkileşimdi (Anderson, 2013, s. 58)."

Anderson'ın bu cümlesi ile atıfta bulunduğu ulusal toplulukların yerine futbol taraftarlığını koyabiliriz. Ulusal toplulukların oluşması için kapitalizmin anlamlılı̆g 1 benzer şekilde futbol ve futbol taraftarlığı için de geçerlidir. Futbol taraftarlığının varlığı ve devamı futbolun varlığına balığıdır ki futbol da kapitalist yönetimlere sahip futbol kulüplerinin varlığı ile ancak devamlılığını sağlayabilecektir. Aynı şekilde, ikinci etkileşim unsuru olarak kitle iletişim araçları (matbaa yerine) ve üçüncü etkileşim aracı dilsel çeşitlilik yerine futbol jargonu, futbol taraftarlı̆̆ındaki hayali cemaatin var olmasında ve hayali cemaat üyeleri arasındaki etkileşimin yadsınamaz unsurları arasında yer almaktadır.

$\mathrm{Bu}$ nedenle, medya futbol taraftarları için oldukça değerli bir iletişim alanı oluşturmuştur. Yeni medya ise bu iletişim biçimine "etkileşim"i eklemiştir. Bu durum bir hayali cemaat olarak futbol taraftarlığı için geleneksel medyanın yerini yeni medyanın alıp alamayacağını sorunsalını akla getirmektedir.

\section{Bulgular ve değerlendirme}

\subsection{Yöntem ve araştırma grubu}

Çalışmada bir nitel araştırma yöntemi olan odak grup görüşmesi kullanılmıştır. Çalışmadan daha nesnel ve geçerli veriye ulaşmak amacıyla Türkiye'deki iki farklı odak grup çalışması yapılmıştır. Bu gruplardan biri homojen (aynı takımı tutanlar), biri de heterojen (farklı takımların taraftarları) yapıya sahiptir. Araştırmaya katılan taraftarların yaş aralığı 21-30 şeklindedir.

\subsection{Bir hayali cemaat olarak taraftarlık ve ulus bağıntısıi}

Anderson'ın ulus tanımında olduğu gibi, taraftar olan birey için de tuttuğu takım diğer takımlara göre daha egemen bir yapıya sahiptir. Örneğin odak gruba katılan bir Beşiktaşlı için Beşiktaşlı olmak başlı başına bir taraftarlığın tanımı iken, Galatasaraylı bir taraftar için ise benzer şekilde Galatasaraylı olmak diğer takımlara yönelik üstünlüğün ifadesi haline gelmektedir. Odak grup çalışmasına katılan ve aynı takımın taraftarları olan grupta bir kişi taraftarlığını şu şekilde ifade etmektedir: "Taraftarlıktan taraftarliğa değişir ama Beşiktaşlılık başlı başına bir ayrıcalık, mesela ben yolda gelirken Beşiktaşlıları gördüm Allah'ıma şükrettim iyiki Beşiktaşlıyım dedim"

Anderson'ın ulusun sinırlı olarak hayal edildiği görüşünde olduğu gibi, futbol taraftarlığı da sınırlı bir gurubu ifade etmektedir. Futbolun kendisi diğer spor dallarından ayrılarak toplumsal sinırları daraltırken, belirli bir takımın taraftarı olmak bu daralmayı bir gruba indirgemektedir. Birey herhangi bir ulusun üyesi olduğu gibi bir futbol takımının da taraftarı olmaktadır. Dahası bir birey nasıl ki ait olduğu ulusa sımsıkı bağlı olabiliyor ise bir taraftar da tuttuğu takıma aynı şekilde bağl1lık göstermektedir.Örneğin çalışmaya katılan bir taraftar "maç izlerken o zaman içinde hiçbir şey ile ilgilenmiyorum, kuzenimin düğ̈̈nü Galatasaray'ın maçı ile aynı saate denk 
Ay, A. (2017). Bir hayali cemaat olarak futbol taraftarının geleneksel ve yeni medya kullanımının karşılaştırılması. International Journal of Social Sciences and Education Research, 933-944.

geldi, dügüne gitmedim” diyerek, adeta ulusu için bir savaş veren asker gibi tüm özel yaşam pratiklerini veya etkinliklerini tuttuğu takımın maçı için ertelemektedir. Tutulan takım taraftarlığının değişimi veya neden o takımı tuttuğu tartışma konusu olarak bile sunulamayacağını şu sözlerle ifade etmektedirler: "Takım taraftarlı̆̆ tartışmaya çok açık konular değil, bir insanın dinini değişstirmek gibi bir şey bu, Galatasaraylllık, babadan gelme diye bir şey var. Ne deseniz bu değişmez. "Bir başka taraftar ise, "Taraftarlık deyince tabela taraftarlı̆̆ değil, mesela bir kadını çok seviyorsunuz ama size çocuk veremiyor onu terk mi edeceksiniz hayır. Taraftarlık da böyle bir şey" demektedir.

Bunun yanında, tıpkı bir ulusu sevmenin koşulu savaşlarda yenilgi veya mağlubiyete bağlı olmadığı gibi taraftarlık duygularının da değişken olmaması durumu görüşmelerde dikkati çekmektedir. "Taraftarlığımız başarı endeksli değildir..." cümlesi buna örnektir. Ayrıca bir ulusta üyesi olunan hayali cemaat dışında kalan uluslara karşı ilgi ve sempatinin düşük olması gibi, futbol taraftarları için de diğer takımlara yönelik ilgi ve sempatinin az olduğu görülmektedir. Bir Beşiktaş taraftarının şu cümlesi bu duruma örnek teşkil etmektedir: "Diğer takım taraftarları hiçbir şey ifade etmiyor."

Benzer şekilde, bir ulusun varlığı için milliyetçi duyguların yer alması gibi, bir taraftar grubu için de aynı takımın taraftarı olmak ortak duygular etrafında bir araya gelmeyi sağlamaktadır. Çalışmaya katılan farklı takım taraftarlarının aşağıdaki cümleleri buna örnektir:

"Dünya kadar derdimiz oluyor futbol bir kaçış noktasl... Ona vefalı olman lazım, taraftarlı bir vefa gibi bir şey... Bu Galatasaraylı sevip, Fenerbahçeliyi sevmemek değil, sadece Galatasaraylıyı daha çok sevmek. Tanımadiğın kişiler içinde Galatasaraylılık referans..." Metroda hiç tanımadığın biri Galatasaray forması giymiş gülümsüyorsun, hiç tanımadı̆̆ın adama kardeşinmiş gibi gülüyorsun... “

"Maçta gol oluyor yanındakine sarllyyorsun, tanımıyorum ama Fenerbahçe maçında gol oldu yanımdakine sarıldım, 'çak' yapıyorsun... Maç bitiminde merdivenlerde biri ile muhabbet ediyorsun, bir daha belki görmeyeceksin... Kim bilir nereden geldi, belki farklı şehirden..."

\subsection{Geleneksel medya ve sosyal medyanın taraftarliğı pekişstirmedeki rolü}

Futbol taraftarının, taraftarlığını pekiştiren unsurlar aynı zamanda bir sosyalleşme ortamı sağlamış olmaktadır. Kavram olarak sosyalleşme, bireyin fizyolojik ve biyolojik gelişimin yanında toplumsal anlamda da şekillenmesini anlamına gelmektedir (Çoştu, 2009, s. 119). Bu anlamda, taraftarlık olgusu etrafinda kurulan hayali cemaate üye birey de bu yolla sosyalleşebilmektedir. Odak grup çalışmalarının katılımcılarının aşağıdaki cümleleri bu durumu ortaya koymaktadir:

"Bizim bir grubumuz var her maç toplanıyoruz, bunun sebebi sadece Beşiktaş... En büyük sosyalleşme ortamımız..." "Mesela ben falanca kişiyi hiç tanımıyorum, Beşiktaş sayesinde tanıdim"

“...Şairler parkına gidelim, yedi milletten insan buluruz, kesin buluruz, ırk, din vs fark etmez hepimiz Beşiktaşliyız... Buralar sosyal bir ortam...”

Futbol taraftarları için tuttukları takımın diğer taraftarları ile bir araya gelmeleri sosyalleşmeyi sağlayan unsurlar arasındadır ancak taraftarın sadece maç için bir araya gelmesi üyesi olduğu hayali cemaate bağlılığını pekiştirmeye yetmeyebilmektedir. Çünkü bir takımın yüzbin- 
Ay, A. (2017). Comparing traditional media and new media use of football supporters as an imagined community. International Journal of Social Sciences and Education Research, 933-944.

lerce taraftarından yalnızca birkaç bini tribünde yer alabilmektedir. Diğer taraftarlar için takımı hakkında bilgi almak, maç sonuçları, transferleri ve futbola dair diğer gelişmeleri öğrenmek için kitle iletişim araçlarına ihtiyaç duymaktadırlar. Ayrıca maça giden taraftar için de haftanın geri kalanı ya da maça gidemediklerinde takımları hakkındaki gelişmeleri öğrenmek için yine kitle iletişim araçlarına ihtiyaç duymaktadırlar. Kitle iletişim araçları bireyin taraftarı olduğu takıma dair gelişmeleri iletmesinin yanı sıra, aynı takımı tuttuğu diğer taraflarla da iletişim halinde olmasını sağlayabilmektedir. Dolayısıyla, bir taraftar için kitle iletişim araçları da sosyalleşme aracı haline gelebilmektedir. Çalışmaya katılan bir taraftarın şu sözleri bu duruma örnek olarakverilebilir: "Bazen taraftar grupları oluyor, mesela ÜNIFEB var, Fenerbahçeli üniversitelileri, onların internet siteleri var toplanmalar için bilgi aliyorsun ya da telefona mesaj geliyor..."

Taraftarlarına geleneksel medya aracılığı ile ulaşan futbol, birey için kendini yeniden inşanın da aracı haline gelmektedir. Örneğin bir taraftarın şu sözleri hem ait olduğu hayali cemaate yönelik bağlılığını göstermesi açısından hem de bireyin yeniden üretimi için anlamlıdır: “...sonuçta sinirlenebiliyorsun da çok mutlu da olabiliyorum, tamamen kaçış noktası benim için, Lig Tv'den bir buçuk saat maç izlemekte, sonrasinda gazeteden okumak da tamamen dertten tasadan uzaklaştırtyor ... o yüzden çok çok klymetli benim için yeri dolmaz..."

Bunların yanında, kitle iletişim araçlarının özellikle de yeni medyanın farklı takım taraftarla$\mathrm{r} ı$ arasında bir çekişmeye hatta nefret söylemine varan içeriklerin oluşmasına neden olduğu bilinmektedir. Bu durum, bir ulus içinde gelişen milliyetçi duyguların farklı etnik kimliklere ya da farklı ülke insanlarına yönelik olumsuz söylemlerini hatırlatmaktadır. Bu söylemlerin bireyin ilgili hayali cemaate aidiyetini pekiştirdiği de yadsınamayacak bir gerçektir. Ancak bu gerçekleşirken bir yandan da hayali cemaatler arası bir kutuplaşmanın da ortaya çıktığı söylenebilir. Futbol taraftarları arasında bu gibi etkilere neden olan en önemli araç ise sosyal medya olduğu çalışmaya katılan taraftarların ifadelerinden de anlaşılmaktadır. Aşağıdaki söylemler taraftarlık hissiyatının ortaya çıktığı zamanlarda ve ortamlarda nasıl bir etki alanı oluşturduğuna örnek olarak gösterilebilir:

"Rakip takımla maç saatleri dışında herhangi bir sorunumuz yok ama sosyal medyada düşünceyi serbestçe ifade etme kısmı çok sinir bozucu olabiliyor. Hiç beklemediğin bir insandan bir laf geliyor sinir küpü oluyorsun... Zaten o an üzgünsün mesela daha da üzüyor veya sinirlendiriyor..."

"Sosyal medyada şöyle bir şey var, örneğin ben Burak ile birlikte iken Burak’ı kırmayacak şeyler söyleyebilirim ama sosyal medyada rakip takıma karşı empati özelliği tamamen ortadan kalklyor. Direkt şey bekliyorsun, Fenerbahçe maç kaybetsin de ben ona laf söyleyeyim. Galatasaray kaybettiğinde Fenerbahçeli arkadaşlarım ne yazmış diye bakıyorum, sinirlenmek için de girdiğim oluyor."

"Sosyal medyayı kullaniyorsan özellikle bir grubu takip etmesen de mutlaka bir yerde karşına çıkıyor takıma dair içerikler. Galatasaray için insanlar bir şeyler yazıyor vs hoşuma gidiyor. Benim kadar Galatasaray’ı düşünenleri görünce mutlu oluyorum."

Öte yandan, sosyal medya ortamlarının taraftarın söz hakkını artırdığı ve geleneksel medya aracılığı ile ulaşamayacağı isimlere ulaşma, sesini duyurma imkanı sağlayarak taraftarlık hissiyatını pekiştirdiği de çalışmaya katılan taraftarların söylemlerinden ve ifade biçimlerinden ortaya çıktığı söylenebilir. 
Ay, A. (2017). Bir hayali cemaat olarak futbol taraftarının geleneksel ve yeni medya kullanımının karşılaştırılması. International Journal of Social Sciences and Education Research, 933-944.

"Twitter'da taraftarlar yoğun bir şekilde Drogba'nın alınmasını istedi ve aldık. Yine taraftarların yoğun twitleri sayesinde ilk defa bir Galatasaray yöneticisi halka açılsın dedi"

"Quaresma sosyal medyadaki twitler ile geldi."

Bunun yanında, taraftarın sosyal medya aracılığı ile fiziksel ortamlarda edindiği deneyimi ve taraftarlık aidiyetini sanal ortamda da hissettirdiği ya da yeni medya teknolojisi sayesinde bu tecrübeyi anlık olarak yaşatabildiği belirtilebilir. Çalışmaya katılan bir futbol taraftarının, "sosyal medyadan özellikle twitter da tribün kültürünü oraya taşıdıkları için ulaşlyorsun, takip ediyorsun aracı oluyor bazen direkt bile olmasa" demesi, taraftarlık hissiyatını sosyal medya arac1lığı ile yeniden yaşamasına örnek iken, diğer bir taraftarın, "takımın web sayfalarına vs illa yazıyoruz... Periscopu da kullanıyorum, izleme imkânı olmayanlar için kullanıyorum evimde maçı izlerken belki izleme imkânına sahip olmayanlar vardır diyerek açıyorum, birileri faydalansin" ifadeleri, futbolun bir araya getirici yönünü geleneksel medyadan yeni medya teknolojisi aracılığ neksel medyanın -futbol lig maçlarının yayıncı kuruluşları büyük ölçüde ücretli olması nedeniyle- tekelci yönünü yeni medya ile bir yönüyle ortadan kaldırmaktadır.

Yayıncı kuruluşların ya da buna bağlı olarak geleneksel medya kuruluşlarında yer alan programların tek yönlü iletişim eğilimli oldukları düşüncesi bazı taraftarların söylemlerinde belirginleşmektedir. Bu durum sosyal medyanın taraftarlık üzerindeki rolünü güçlendirdiği söylenebilir. Ayrıca bazı sosyal medya hesaplarının ve kullanıcılarının kanaat önderi vasfı taşıdıkları görülmektedir. Bu durum önceleri geleneksel medyanın sıklıkla yer verdiği kanaat önderlerinin görüşlerinin de yeni medya platformlarında yeniden üretildiğini göstermektedir. Odak grup çalışmasına katılan futbol taraftarlarının aşağıdaki ifadeleri bu durumu özetlemektedir:

"Takımin sosyal medya hesaplarl var... bizi kanalize eden bunlar. Biz de onlarin bilgisi olmadan hashtag başlatmak istemeyiz, başlatmayız. Bu hesaplardan ne gelirse gelsin güveniyoruz, onları tanıyoruz zaten... Beşiktaş haberlerini gazeteden okumuyoruz, haber1903 var web sistesi oradan takip ediyoruz... Sosyal medyada çok güçlüyüz. Güçlü hesaplar var onlar taraftarl yönlendiriyor. Beşiktaşlı spor muhabirleri çok aktifler Twitter'da onları takip ediyoruz."

"Beşiktaş muhabirleri sosyal medyada çok daha Beşiktaşlılar, yani kendi Beşiktaşlılık kimliklerini daha net ortaya koyabiliyorlar. Sosyal medyada Beşiktaş taraftarının daha iyi organize olmasinda büyük rol oynuyorlar."

Bunun yanında, geleneksel medyaya karşı genel anlamda olumsuz bir tavra sahip taraftarların tüm tutumlarına rağmen televizyon kanallarında yayınlanan spor programlarını izledikleri görülmektedir. Örneğin, "her şey şov işine dönüştü.." "ben nefret ediyorum ama izliyorum da, mesela Galatasaray yeniliyor 'bozguna uğradl' diyor Fenerbahçe olsa 'mağlup oldu' yazlyorlar." diyen ya da bu düşünceye katılan taraftarlar aynı zamanda bu programları izlemekte ya da gazetelerde çıkan haberleri takip etmektedir. "Yanlı tutumlar ekran karşısında sinirlendiriyor ama sinirleniyorsun ama her hafta da izlerim... neden izlemeyeyim." İfadelerinden de anlaş1lacağı üzere, bir futbol takım taraftarı için kendi takımı hakkında bilgi almak her türlü yargının önüne geçebilmektedir. Ancak odak grup çalışmalarında dikkati çeken bir diğer unsur da televizyon programlarına yönelik tüm eleştirilere rağmen, ilgili taraftarların, izledikleri programların spikerleri ya da yorumcu olarak katılan konukların tuttuğu takım kendi takımları olmaktadır. $\mathrm{Bu}$ durum, taraftar ile spiker/yorumcu arasında ilgili hayali cemaatin oluşturduğu aidiyet ve 
Ay, A. (2017). Comparing traditional media and new media use of football supporters as an imagined community. International Journal of Social Sciences and Education Research, 933-944.

kimliğin aynı olmasından kaynaklanan bir yakınlığın etkili olduğunu göstermektedir. Ayrıca, aşağıdaki örneklerde de görüldüğü üzere taraftarlar sosyal medyayı bir örgütlenme aracı olarak da kullanmaktadır.

"Sosyal medya aracılığı ile bazı etkinliklere katıllyoruz, whatsapp gruplarl ile de haberleşiyoruz. Örneğin Fenerbahçe'nin şike olayları olduğu zaman yürüyüş olduğunu oradan öğrenip, katıldım"

"Sosyal medya çok geniş bir kitleye ulaşıyor, ... Ben de katıldım bir yürüyüşe, ayrıca atılan hashtaglere de katıllyorum."

"Sosyal medya aracıllğ̆lyla toplanmalar örgütleniyor...” "Örgütlenme için çok güçlü... Örgütlenmenin tek sebebi twitter..."

"Diyelim ki maça Bülent yıldırım atandl, diyelim ki Beşiktaş o yönettiğinde 7 maç kaybetmiş 5 maş kazanmış vs o hafta o hashtag cumartesiye kadar yürür 'Bülent Ylldırım gözümüz üzerinde' diye.." Burada sosyal medya aracılığ ile hayali cemaat üyeleri ilgili kişi üzerinde baskı kurarak, normalde medyaya atfedilen "baskı grubu" özelliğini gerçekleştirmiş olmaktadırlar. Bu şekilde, sosyal medya ile taraftarlığın güçlendiği ve pekiştirildiği belirtilebilir.

Bunun yanında çalışmaya katılan taraftarlardan bazıları için yeni medyanın hızı taraftarlığını pekiştirmede katkı sağlasa da sanal bir gerçeklik sunmaktadır. Bu durum Walter Benjamin'in "sanatın bircikliğini yitirdiğì" ifadesini hatırlatmaktadır. Benjamin'e göre, sanat eseri fotoğrafin ortaya çıkmasıyla çoğaltılabilir hale gelmiş ve tek bir eser olma özelliğini, erişilemezliğini yitirerek, bircikliğini yitirmiştir (Benjamin, 2002, s. 58-65). Yeni medya ile taraftarlık hissiyatı ve tutulan takıma sadakat sorgulanır hale gelmiştir. Odak grup katılımcılarından biri bu durumu şöyle ifade etmektedir:

"Aynı şeyi herkes yapabilir, sıradanlaştırdı her şeyi, mesela Galatasaray ile ilgili eski toplanmalar daha samimi idi çünkü o kişilere bizzat ulaşman gerekiyor ki gelebilsin" "poster biriktirme vardı... Gazete biriktirme... Örneğin UEFA kupası kazanımı sonrası gazete manşetlerini almış babam ... Kıymet gerektiriyordu bu yok sosyal medyada ..."

"maçtan sonraki günlerde Fotomaç almayı çok özledim, Galatasaray şampiyon olduğunda verilen posterleri çok özledim, gelenekseli gerçekten tercih ederdim yani.."

"geleneksel medyanin tadl farklı oluyor... ben taraftar olarak transfer haberlerini takip etmek için transfer döneminde sabahları gider gazete alırdım ve sadece benim için Galatasaray haberleri en önemlisidir. Sondan başlarsını gazeteye, Galatasaray en sonda oluyor, bakarsın gazeteye ve biter. Yeni medya, bunu hızlandırdı, şu an telefonumada webaslan uygulamast var ve şu an takımdaki bir futbolcu sakatlanmış ben bunu öğrenebiliyorum ama onun tadı farklıydı, kıymetliydi. Ama şöyle bir durum var orada tek yönlü olduğu için destekle ya da destekleme sesini duyuramazsın ama yeni medyada yorum yazabilirim... Mesela taraftar gruplarına çok rahat iletişime geçebiliyorsun. Bu yönden artısı var ama eskinin tadının her zaman farklı oluyor."

"sosyal medya bazında, inanılmaz mutsuzum, eskiden insan, yatmadan önce düşünüyorsan acaba yarın ne okuyacağım diye düşünüyorsun... Ama şimdi insanlar futbolcunun biri sakatlanlyor "iyi gebersin, ona boşuna para veriyoruz deniyor" 
Ay, A. (2017). Bir hayali cemaat olarak futbol taraftarının geleneksel ve yeni medya kullanımının karşılaştırılması. International Journal of Social Sciences and Education Research, 933-944.

Bu yorumlara rağmen, futbol taraftarları için sosyal medyanın sağladığı erişimin yadsınamaz bir yere sahip olduğu ancak geçmişe özlem duyulduğu görülmektedir. "Eskinin tadı bir başka ama yurtdışındaki futbolculara hayranlık duyduğumuz antrenöre veya futbolculara ulaşma açısinda bize çok farkl şeyler sunuyor." ifadeleri ve aşağıda yer alan söylemler bu durumu ortaya koymaktadir.

Sosyalleşme açısından daha etkili" sosyal medya hayatımızı çok kolaylaştırıyor, bu akşam istesem twitterdan 500 kişi toplayıp yürüyüş yapabilirim. Ama o heyecanı aldı bizden. İstediğimiz her şey elimizin altında artık.”

"Yeni medyayı geleneksele tercih ederim çünkü daha kolay ama bizi monotonlaştırdl. " insan kalitesini düşürdü. TRT maçın montajını yapsın da izleyelim derdik... Ama artık biri paylaşlyor ve anında izliyorsunuz o heyecan kalmadl"

Çalışmaya katılan futbol taraftarların ifadelerinde sosyal medyanın diğer bir olumsuz yönü ortaya çıkmaktadır.

“Çok vahşi olunabiliyor... Geçen sene Semih'in gözüne mangal kömürü kaçtı, adam kör kalıyordu ama insanlar... Neler dedi. O çocuk bunları okuyor, 22 yaşında bir çocuk bu ne yapıyorsunuz siz? Öyle şeyler oluyor ki, keşke kapatılsa!"

"Medya taraftarllğg törpülüyor, çünkü maddiyat açısından baklyor maneviyat olarak bakmıyor. Ama tabi onların işi maddiyat ama bizim işimiz de maneviyat"

"sosyal medyayı kullanış amacı önemli, bölmek istiyorsanız bölmek daha kolay çok fikir ayrlliklarl var..."

Anderson'1n “18. Yüzyılın sonunsa doğru milliyetçiliği “üreten” şeyin dinsel kesinliklerin aşınması (Anderson, 2013, s. 26)" olduğunu belirtmesi gibi, geleneksel medyada oluşabilen tekelci eğilim veya objektifliğin zedelenmesi durumu da, yeni medya ortamlarının taraftarlarca tercih edilmesini ve taraftarlıklarını güçlendirmelerini sağlamaktadır. Buna örnek olarak Beşiktaş taraftarlarının şu sözleri verilebilir:

"Geleneksel medya bize karşı biz de sosyal medyayı kullanıyoruz..." "Geleneksel medyadan hiçbir umudum yok, biz o yüzden sosyal medyadayız..." "Geleneksel yayıncılar toplumun belli bir kesimini dışlamasa internet medya bu kadar patlamaz",

Odak grup çalışmasına katılan taraftarların yurtdışındaki takımlarla olan iletişiminde yine kendi takımlarına ait simgelerin hakim olduğu takımlara yönelik bir sempatinin geliştiği görülmektedir. Bu durum yakın kimliklere sahip hayali cemaatlerin arasındaki bağın güçlendiğini ortaya koymaktadır. Buna örnek olarak Beşiktaş taraftarlarının aşağıdaki cümleleri örnek verilebilir.

“... Paok u çok severiz onlar da siyah beyaz-fener maçında bizden de adamlar gitmişti. Sosyal medyadan haberleşiyoruz. " olimpiyakosu paok yenmiş twitterda şimdi sıra sizde dediler" her şey twitterda oluyor facebookta falan değil "

\section{Sonuç}

Yeni medya aracılığı ile bir futbol taraftarının, üyesi olduğu hayali cemaatin diğer üyelerine daha kolay ulaşabildiği ve geleneksel medyanın tek yönlü iletişiminden uzaklaşarak kendi özel 
Ay, A. (2017). Comparing traditional media and new media use of football supporters as an imagined community. International Journal of Social Sciences and Education Research, 933-944.

alanlarını inşa edebildikleri gözlemlenmiştir. Bu durum aynı zamanda bir futbol taraftarı için aidiyetin pekiştirilmesini daha olanaklı hale getirmektedir. Geleneksel medya ile çoğunlukla tuttuğu takımın egemenliği dışında kalan bir söylem oluşurken, yeni medya aracılığı ile futbol taraftarı kendi söylemini üretebilmektedir. Bu durum özellikle de geleneksel medyada yeterli temsil bulamayan takım taraftarlarında daha belirgin hale gelmektedir. Çalışmada elde edilen bulgularda da belirtildiği gibi, bazı taraftarlar neredeyse sadece sosyal medya ya da takımının web sayfaları aracılığı ile futbola ve tuttukları takımlara dair gelişmeleri takip etmektedirler.

Bunun yanında, bir futbol takımı hakkında edilmeye çalışılan içeriğin sosyal medya aracılığı ile çok hızlı bir şekilde ve çok geniş bir kitleye ulaşabilmesi, aynı zamanda o içeriğin daha kısa zamanda tüketilmesini de beraberinde getirmektedir. Geleneksel medyada ise, daha uzun sürede ulaşılması ve daha dar bir kitlenin bu gelişmeleri takip edebilmesi içeriği daha önemli ve özel hale getirmektedir.

Diğer yandan, Anderson'ın sözünü ettiği kapitalist yayınc1lık anlayışı günümüzde yeni medya ile birlikte farklı bir boyuta taşınmıştır. Artık yüzyıllarca dinlere ve farklı medeniyetlere dayalı cemaatlerin değişiminden değil, anlık gruplaşmalardan, anlık/kısa süreli cemaatleşmelerden söz etmek mümkün hale gelmiştir. Kendisi de bir hayali cemaat olan futbol taraftarlığı da yeni medyanın bu anlık/kısa süreli oluşumlarından etkilenmektedir. Bu durum taraftarlık, içeriğini de etkilemektedir. Taraftar haberi gazete ya da televizyondan henüz alamamışken, aynı haber için sosyal medyada bir hashtag açılmış ve tartışma başlatılmış olabilmektedir. Ayrıca taraftar geleneksel medyadan ulaşmadığı birçok isme, sosyal medya aracılığıyla sesini duyurabilmektedir. $\mathrm{Bu}$ durum taraftarın üyesi olduğu hayali cemaate aidiyetini daha hızlı pekiştirmektedir. Çünkü artık hayal edilene bir tık uzaklığındadır, dahası yakınındadır.

\section{Kaynakça}

Anderson, B. (2013). Hayali Cemaatler Milliyetçiliğin Kökenleri ve Yayılması. (İ. Savaşır, Trans.) İstanbul: Metis Yayıncilik.

Aziz, A. (1982). Toplumsallaşma ve Kitlesel İletişim. Ankara: Ankara Üniversitesi Basın Yüksek Okulu Yayınları No:2

Benjamin, W. (2002). Pasajlar. (A. Cemal, Trans.) İstanbul: YKY Yayınları.

Çoştu, Y. (2009). Toplumsallaşma kavramı üzerine sosyolojik bir değerlendirme. Dinbilimleri Journal, 117-140.

Ritzer, G., \& Stephisky, J. (1992). Sociological Theory. (Ü. Tatlıcan, Trans.) McGraw-Hill,Inc.

Türkiye Futbol Federasyonu Yayınları. (1992). Türk Futbol Tarihi. Türk Futbol Tarihi Cilt-1. İstanbul: Türkiye Futbol Federasyonu Yayınları 
Ay, A. (2017). Bir hayali cemaat olarak futbol taraftarının geleneksel ve yeni medya kullanımının karşılaştırılması. International Journal of Social Sciences and Education Research, 933-944.

\section{Extended abstract in English}

Individuals interact with the society they live in. This interaction holds some important agents for socialization and sense of belonging. Family, school, workplace, and sports activities are some of the social platforms enabling socialization. These spaces, as well as holding some reinforcing agents for the sense of belonging of the individual, they also create a harmonical space for all the people having a common culture, belief, and value system. Especially sport activities are important to mention as to constitute Benedict Anderson's "imagined community".

Besides it is widely acknowledged that media has an important role in constituting imagined communities, as well as its role in making people socialize. Addressed by Anderson through capitalist publishing, imagined community has been positioned and pictured in a new and different way by the new media along with traditional media. It is a continuing debate however, whether which media is more actively constituting and shaping imagined communities.

After every new type of mass medium emerge, the unknown future of old mass media has come to the surface, while radio, seen as a threat for newspaper, and then television, seen as a threat for cinema have never been able to replace their ancestors considering the demand from audience. Nevertheless, emerged late nineteenth century, computer technologies and accordingly internet have created a massive effect which would cause renaming the media as "traditional", and turned out to be the "new media" itself. Therefore, the debate whether old mass media will have a future replaced by a comparison between traditional and new media. The process so far has created the fastest written and witnessed history of mass media.

Anderson's imagined community notion is also used for groups nourishing from common dynamics while being left out of the definition of nation. Basically, a group is named an imagined community when it bears same senses, same fortunes, same belonging agents uniting on a common ground despite the lack of getting to know all the group members. From this point of view, aiming a very broad mass, football creates an imagined community in itself within all sports activities and events. The main problematic of this study is to determine whether and for what reason football supporters choose one media over the other as in traditional/new media, which has a big influence on sense of belonging and socializing process.

Mass media has always been a good and valuable space of communication for football supporters. New media has added "interaction" to their communication process. Traditional reader-supporter, audience-supporter and viewer-supporter have united in a single platform thanks to new media. Emerging of social networks with a continuously expanding penetration into daily lives has increased this interaction. Supporters now are able to reach out to/communicate with football players, club managers, sport papers and sport journalists which used to be not possible in their daily lives. This aspect brings about the problematic whether football supporters as an imagined community will replace new media with traditional media. Nevertheless, it is not surprising to discuss the role of both media in the future in case of football supporting. 
Ay, A. (2017). Comparing traditional media and new media use of football supporters as an imagined community. International Journal of Social Sciences and Education Research, 933-944.

In this study, the mass media choice of football supporters has been determined through qualitative research method-based focus group, as to discuss how those mass media effect strengthening the sense of belonging in their imagined community.

The study has observed that a football supporter access other community members easier through new media than traditional media, while they are able to construct their private spaces away from the one-way communication imposed by traditional media, which at the same time makes more possible the belonging reinforcement for football supporter. Football supporters are able to construct their own discourse through new media, while traditional media causes a discourse out of the hegemony of their team. This is especially more obvious with football supporters underrepresented on traditional media. As seen in the findings of this study, some of the supporters nearly and solely follow the news about football in general and the team they support through social media or their team's web sites.

Beside this, the fact that some content about a football team reach a very wide mass through social media very fast also make that content fast consumable, while in traditional media the content turns out to be more important and special since it takes long time to access with a narrower mass being able to follow the news.

On the other hand, the capitalist sense of publishing stated by Anderson has gained a new dimension with new media's penetration into life. Now it is possible to talk about immediate groupings, immediate/short term communities instead of a long term transformation of communities based upon religions and various civilizations. Football supporting itself as an imagined community is being influenced by these immediate and short term occurrences on new media, which in turn effects supporting content. When the supporter has not accessed the news yet via paper or television, the same news emerge on social media with a hashtag, already been discussed about. Moreover, supporters easily reach celebrities via social media, something which traditional media do not enable, which in a more immediate way reinforce football supporter's sense of belonging in an imagined community, because the supporter now is a click away from the imagined, what is more, a click closer. 